\title{
Happy Birthday Chromatographia
}

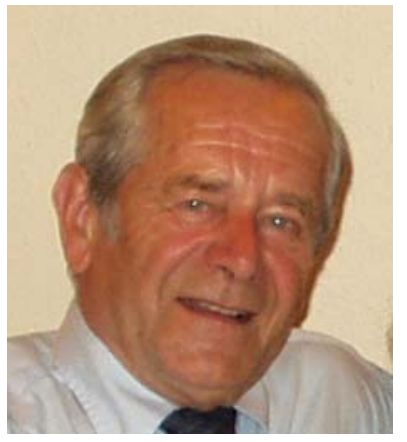

Chromatographia is celebrating its 40 years birthday! Why did we found this journal in 1968 ?

The analytical applications of chromatography started to explode in the 1950s and 1960s. Chromatography conferences round the world attained a very high standard of quality. The yield of information, understanding, new modes of chromatography and its critical application for solving problems reached sky-high proportions for the lone participant. Back at home experiments were started to find out if and how to change the existing analytical procedures and instruments. At that time regulations were no hold up of progress. Quite a lot of decisions about how to reorganize old analytical procedures or to enter into new fields of application became time critical. There was a growing need to hear about new hardware promptly and to get data about the best possible solutions of problems by this new exciting technique in good time. Many discussion groups were founded in order to get the best possible information about the background and the likely immediate future of chromatography quickly. We needed more rapid communication.

In addition, we realized, that there was often a strong language barrier. We realized the limitations of language polishing and timing. Another problem was a high degree of missing literature exchange between the countries from east to west and vice versa. We needed a new chromatography journal in Europe where editors from different countries could work together effectively. Thus it was that after a few months of intensive exchange of ideas and communication to nail down a helpful concept and to find a team of editors willing to bring Chromatographia to life as "An International Journal for Rapid Communication in Chromatography and Related Techniques".

My first chromatographer colleague who said yes to the ideas and the concept was the mother of chromatography, Professor Erica Cremer, of Innsbruck, Austria. One of the earliest pioneers of chromatography, Professor G. Hesse of Erlangen, Germany, also agreed to join the Editorial Board. Finally the top chromatographers of that time from many European countries and a few from the United States - thirty in all-met regularly at editorial meetings for further improvements to the journal. In order to get rid of language barriers each publication had to start with a concise summary in English, French and German. Chromatographia published green page summaries about the fundamentals of each paper fully translated into English, German and French in order to help newcomers in chromatography bridge language barriers. Thus we needed native language chromatographers as regional editors from England, France, Russia, Hungary, Czechoslovakia and Germany. Besides Original Papers we planned to publish Short Communications, Letters to Editors, Review Articles, Green Pages and scientific articles by instrument manufacturers.

From the beginning up to the present Chromatographia has successfully achieved its original aims with the able assistance of the same publishing house, Vieweg, based in Wiesbaden.

I would like to take this opportunity to thank readers, authors, editors and the publisher for 40 years of friendly cooperation. This must continue, chromatography is ever more and more important and new problems constantly arise waiting to be solved by this wonderful technique.

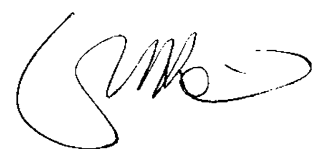

R. E. Kaiser,

Founder of Chromatographia 